Original Article

\title{
In vitro radiosensitivity of lymphocytes from high-background radiation area inhabitants in Indonesia: a pilot study using the $\mathbf{G}_{\mathbf{0}}$ micronucleus assay
}

\author{
Dwi Ramadhani ${ }^{1,2 *}$, Sofiati Purnami ${ }^{1}$, Siti Nurhayati ${ }^{1}$, Eko Pudjadi ${ }^{1}$, Mukh Syaifudin ${ }^{1}$ \\ ${ }^{1}$ Nuclear Medicine Technique and Radiation Biology Division, Center for Technology of Radiation Safety and Metrology (PTKMR), \\ National Nuclear Energy Agency (BATAN) \\ ${ }^{2}$ Doctoral Program for Biomedical Sciences, Faculty of Medicine, University of Indonesia
}

\begin{abstract}
The Mamuju area has recorded a higher than average natural radiation dose compared to other regions in Indonesia. It is possible that inhabitants of Mamuju developed the radioadaptive response (RAR). To prove that the RAR was developed in Mamuju inhabitants, evaluation of lymphocytic radiosensitivity using the $\mathrm{G}_{0}$ micronucleus $(\mathrm{MN})$ assay was conducted herein. The $\mathrm{MN}$ frequencies in peripheral blood lymphocytes before and after exposed to $1.5 \mathrm{~Gy}$ radiation at a dose rate of $0.38 \mathrm{~Gy} / \mathrm{min}$ were assessed from 11 samples of Botteng Village, Mamuju inhabitants and control groups. These treated cells were then cultured and exposed to cytochalasin-B to arrest cells during the cytokinesis stage. The mean number of MN induced by radiation per 1000 binucleated cells (BNC) was evaluated for both Mamuju inhabitants and control groups. The lymphocytic radiosensitivity was calculated using standard deviation (SD) of the mean value (MV) of the number of MN induced by radiation found in the control group. Based on the SD and MV values, individual lymphocytes were classified as "resistant", "sensitive", or "normal" if the mean of MN induced by radiation was $\leq$ MV - $(2 \times \mathrm{SD}), \geq \mathrm{MV}+(2 \times \mathrm{SD})$ or in between, respectively. The results showed that lymphocytes from six samples in Botteng Village inhabitants were categorized as resistant and five samples were normal. In contrast, all samples in the control group were demonstrated to have normal sensitivities. The study results also revealed that lymphocytic radiosensitivity was not correlated with age and gender, which was probably because of the small sample size used in this study. Further investigation with a larger sample number and higher radiation dose should be conducted to validate our findings.
\end{abstract}

Keywords: Lymphocytes, Mamuju, micronucleus, radiation, radiosensitivity

Received: 09 February 2018 Revised: 09 May 2018 Accepted: 14 October 2018

\section{Introduction}

A high-background radiation area (HBRA) is defined as an area where the total cosmic radiation and natural radioactivity in soil, air, water, and other environmental factors can increase the annual effective dose to the public above a predetermined level (Hendry et al., 2009). Until now the average annual effective dose from a natural background radiation exposure across the globe is currently about $2.4 \mathrm{mSv}$ (Mortazavi et al., 2003). However, there are several areas in the world that are considered HBRA, such as Ramsar (Iran), Guarapari (Brazil), Kerala (India), and Yangjiang (China) (Sadiq \& Termizi, 2015). The level of natural background radiation in these areas can reach 3-100 times the worldwide average background dose (Mortazavi et al., 2003).

The Mamuju area in West Sulawesi Indonesia is also known for high radiation dose rates owing to naturally occurring radioactive material (NORM), especially natural uranium (238U) contents. Uranium concentration in Mamuju was on the range of 0 to 1,529 with an average of $25 \mathrm{ppm}$ eU, while the average abundance in the Earth's crust is $3 \mathrm{ppm}$ eU. Several areas in Mamuju have a

\section{* Corresponding Author:}

Dwi Ramadhani

Nuclear Medicine Technique and Radiation Biology Division, Center for Technology of Radiation Safety and Metrology (PTKMR), National Nuclear Energy Agency (BATAN) Phone: +62217513906 Fax: +62217657950

e-mail: dhani02@batan.go.id,dwi.ramadhani81@ui.ac.id radiation dose rate of more than $400 \mathrm{nSv} / \mathrm{h}$, including Ahu, Takandeang, Botteng, Pengasaan, Tande-Tande, and Mamunyu. Three areas (Tande-Tande, Takandeang, and Botteng) were used for settlement, while Ahu, Pengasaan, and Mamunyu only consist of forest and weeds (Syaeful et al., 2014).

Studies of the health status of HBRA inhabitants are a potential source of information on the effects of chronic low dose rate exposure. However, there are two different opinions exist regarding the detrimental effects of low doses radiation exposure. The first opinion states that low dose radiation poses a danger and there is no threshold dose for side effects. The second opinion, there is a threshold dose for side effects of low dose radiation and emphasizes the beneficial or stimulatory effects of low dose radiation based on radiation hormesis and adaptive response phenomena (Mortazavi \& Mozdarani, 2012). Radioadaptive response (RAR) is defined as the biological response where an exposure of low dose radiation (priming dose) to the organism can induce protective mechanisms against the detrimental effects of a subsequent higher radiation exposure (challenging dose) (Choi et al., 2011; Wodarz et al., 2014).

Our previous studies uncovered that there was an insignificant difference in $\gamma-\mathrm{H} 2 \mathrm{AX}$ foci expression, micronucleus $(\mathrm{MN})$ frequencies, and comet tail length in lymphocytes of people living in Botteng and Takandeang Villages, Mamuju compared to NBRA inhabitants (Basri et al., 2017; Nurhayati et al., 2016; Rahardjo et al., 2017). Based on these findings, it is possible that Mamuju inhabitants developed the RAR phenomenon. With this, 
assessment of lymphocytic radiosensitivity can be used to prove the RAR phenomena in Mamuju inhabitants. Until now, the $G_{2}$ and $G_{0}$ chromosomal assays seem to be the most relevant techniques for predicting lymphocytic radiosensitivity (Poggioli et al., 2010). However, the evaluation of chromosomal aberrations is too laborious and time consuming. Thus, the use of another biomarker, such as MN for predicting lymphocytic radiosensitivity, has become a better option in recent times.

The $\mathrm{G}_{0} \mathrm{MN}$ assay performed on peripheral blood lymphocytes exposed to in vitro doses of 2 to $4 \mathrm{~Gy}$ is frequently employed to assess individual radiosensitivity (Baert et al., 2016). The MN assay that evaluates the frequency of $\mathrm{MN}$ in peripheral blood lymphocytes

\section{Methods}

Indoor and Outdoor Gamma Dose Rate Measurement

The indoor and outdoor background gamma radiation measurements were performed by a gamma spectrometer (Exploranium GR-135 Plus) calibrated in the secondary standard dosimetry laboratory under the National Nuclear Energy Agency of Indonesia. In the outdoor gamma dose rate measurements, the detector was placed at least six meters away from the walls of any building nearby and one meter higher than ground level. For indoor measurements inside the houses, the detector was placed one meter higher than ground level with a total exposure time of 10 mins. The average of all measurements across 63 houses from Botteng Village and 10 houses from Keang Village were calculated and considered as the outdoor and indoor gamma dose rates in the Botteng Village as HBRA and Keang Village as control area.

\section{Annual Effective Dose Calculation}

The annual effective dose calculated from the indoor and outdoor background gamma dose rates values by referring to this equation (1) (UNSCEAR, 2000):

$$
E=\left(D_{\text {out }} \times O F_{\text {out }}+D_{\text {in }} \times O F_{\text {in }}\right) \times T \times C C(1)
$$

Where $\mathrm{E}(\mathrm{mSv} / \mathrm{y})$ is the annual effective dose, $\mathrm{D}_{\text {out }}$ and $\mathrm{D}_{\text {in }}(\mathrm{nSv} / \mathrm{h})$ are the average outdoor and indoor gamma dose rates, $\mathrm{T}$ (hr) is time to convert from year to hour (8760 hours), $\mathrm{OF}_{\text {out }}$ and $\mathrm{OF}_{\text {in }}$ are outdoor and indoor occupancy factors $(30 \%$ and $70 \%$ for outdoor and indoor, respectively) and $\mathrm{CC}$ is conversion coefficient $(0.7$ for adults) reported by United Nations Scientific Committee on the Effects of Atomic Radiation (UNSCEAR). The occupancy factor for indoors and outdoors was calculated based on the observation that Botteng Village inhabitants and control samples spent almost $8 \mathrm{~h}$ outdoors and $16 \mathrm{~h}$ indoors.

\section{Blood Sampling}

Eleven healthy adult subjects from Botteng Village, along with Keang Village as a NBRA, were included in this study. Peripheral blood samples were collected by venipuncture utilising heparinized vacutainer tubes (BD Vacutainer Systems). Two vacutainer tubes were obtained from each sample. The study was approved by the Ethics Committee of the National Institute of Health Research induced by radiation exposure could represented the intrinsic cell radiosensitivity. $\mathrm{MN}$ in binucleated cells (BNC) could originate from acentric fragments or chromosomes that are not incorporated in the daughter cell nuclei during mitotic division. The MN assay is hence a promising method for evaluating lymphocytic radiosensitivity because of it is simplicity and reliability of the protocol. It is also less laborious, which makes it a preferred modality when assessing lymphocytic radiosensitivity (Encheva et al., 2012). Here in this study, we aimed to evaluate lymphocytic radiosensitivity of inhabitants of Botteng Village, Mamuju with the $\mathrm{G}_{0} \mathrm{MN}$ assay.

and Development, Indonesian Ministry of Health, number LB.02.01/5.2.KE.051/ 2015, date of January 29, 2015. Informed consent was obtained from all donors. A detailed questionnaire was employed to solicit information on age and occupation. All procedures performed in this study were in accordance with the ethical standards of the National Research Committee and the 1964 Helsinki Declaration and its later amendments or comparable ethical standards. The inclusion criteria of this study were: having complete information on gender, age, no intake of alcohol, no family history of genetic disorders, and no exposure to ionizing radiation except for natural background radiation. The exclusion criteria were having medical treatment, especially that featuring radiation exposure.

\section{Irradiation Procedure}

Whole blood samples in the vacutainer tubes were irradiated in vitro with 1.5 Gy $\gamma$ rays at a dose rate of 0.38 $\mathrm{Gy} / \mathrm{min}$. With this, one vacutainer tube from each sample was irradiated whilst the other tube was sham-irradiated. The irradiation process was carried out at the Secondary Standard Dosimetry Laboratory (SSDL) at the Center for Technology of Radiation Safety and Metrology, National Nuclear Energy Agency of Indonesia. Peripheral blood samples in heparinized vacutainer tubes were placed inside of the box container made from clear acrylic holders with dimensions of $30 \times 30 \times 30 \mathrm{~mm}^{3}$. The box container was equipped with access ports to permit heaters for maintaining the water temperature inside the box at $37{ }^{\circ} \mathrm{C}$ during irradiation and an aquarium circulation water pump for water circulation within the container. The irradiations process was conducted at room temperature.

\section{Go Micronucleus Assay}

Following irradiation, lymphocytes were cultured according to the $\mathrm{MN}$ assay protocol of the official International Atomic Energy Agency (IAEA) publication with minor modifications (IAEA, 2011). Whole-blood samples were cultured for $72 \mathrm{~h}$ in an incubator at $37{ }^{\circ} \mathrm{C}$ containing $5 \% \mathrm{CO}_{2}$. The culture medium consisted of 4.5 $\mathrm{mL}$ of Rosewell Park Memorial Institute (RPMI) 1640 supplemented with $20 \%$ heat inactivated foetal bovine serum (FBS), $1 \%$ streptomycin/penicillin, and $0.1 \mathrm{~mL}$ of 
phytohemagglutinin (PHA). Cytochalasin-B was added to the culture at $44 \mathrm{~h}$ at a final concentration of $6 \mu \mathrm{g} / \mathrm{ml}$. The cells then were centrifuged for 10 mins at $1000 \mathrm{rpm}$ and resuspended in $7 \mathrm{~mL}$ of $0.075 \mathrm{M}$ cold $\left(4{ }^{\circ} \mathrm{C}\right) \mathrm{KCl}$. Subsequently, the cells were centrifuged again for 8 mins at $1000 \mathrm{rpm}$ and resuspended in freshly made fixative consisting of methanol: acetic acid (10:1) diluted 1:1 with Ringer's solution. The cells were then washed with two to three further changes of freshly prepared fixative consisting of methanol:acetic acid (10:1) without Ringer's solution until the cell suspension was clear. The cell suspension then was stored at $-20{ }^{\circ} \mathrm{C}$ for at least for one night until the slide preparation was performed. Fixed cells were dropped onto clean, wet slides, and then dried and stained with $4 \%$ Giemsa solution $(\mathrm{pH}$ 6.8) for 12 mins. The scoring criteria were based on Fenech's publication from 2007. One thousand BNC were scored at a magnification of $400 \times$ for each sample. Further, for each sample, three parameters were calculated based on Encheva et al (2012). The spontaneous (baseline) MN number, $\mathrm{MN}$ number after $1.5 \mathrm{~Gy}$ in vitro irradiation, and radiation-induced $\mathrm{MN}$ were calculated to predict lymphocytic radiosensitivity. The radiation-induced MN was defined by subtracting the spontaneous $\mathrm{MN}$ number from the MN number after irradiation. The procedure was

\section{Results}

\section{Indoor and Outdoor Gamma Dose Rate}

The minimum and maximum gamma dose rates for indoor measurements in Botteng Village were $300 \mathrm{nSv} / \mathrm{h}$ and $1500 \mathrm{nSv} / \mathrm{h}$, whilst for outdoor measurements, they were $300 \mathrm{nSv} / \mathrm{h}$ and $2000 \mathrm{nSv} / \mathrm{h}$, respectively. The average indoor and outdoor gamma dose rates in Botteng Village were $566 \pm 158.02 \mathrm{nSv} / \mathrm{h}$ and $764 \pm 241.43 \mathrm{nSv} / \mathrm{h}$, respectively. In the control area, the minimum and maximum gamma dose rates for indoor measurements were $123 \mathrm{nSv} / \mathrm{h}$ and $220 \mathrm{nSv} / \mathrm{h}$, whereas for outdoor measurements, they were $140 \mathrm{nSv} / \mathrm{h}$ and $180 \mathrm{nSv} / \mathrm{h}$, respectively. The average indoor and outdoor gamma dose rates, respectively, were $162 \pm 31.47 \mathrm{nSv} / \mathrm{h}$ and 151 $\pm 12.86 \mathrm{nSv} / \mathrm{h}$.

\section{Annual Effective Dose}

The average annual effective dose for Botteng Village was $3.83 \mathrm{mSv} / \mathrm{y}$ with a range from 1.84 to $10.12 \mathrm{mSv} / \mathrm{y}$. In the control area, the average annual effective dose was $0.97 \mathrm{mSv} / \mathrm{y}$ with a range from 0.76 to $1.28 \mathrm{mSv} / \mathrm{y}$. The average annual effective dose for Botteng Village without concerning the ingestion and inhalation exposures from radon gas was 3.94-fold higher than the values of the control area and 4.4-fold higher than the effective environmental gamma dose rate based on cosmic rays and terrestrial gamma radiation estimated in the world average report by UNSCEAR in 2008, which was $0.87 \mathrm{mSv} / \mathrm{y}$. performed in all samples. The individual radiosensitivity was calculated using the standard deviation (SD) of the mean value (MV) of the number of $\mathrm{MN}$ induced by radiation found in the control group. Based on the SD and MV values, individuals could be classified as "resistant", "sensitive", or "normal" if the mean of MN induced by radiation was $\leq \mathrm{MV}-(2 \times \mathrm{SD}), \geq \mathrm{MV}+(2 \times \mathrm{SD})$ or in between, respectively.

\section{Statistical Analysis}

$\chi^{2}$-test analysis was applied to verify the statistical difference of the categorical variables (gender) in Botteng Village inhabitants and control samples. Unpaired t-test analysis was employed for the continuous variable, namely ages of the inhabitants in Botteng Village and control samples. The $\mathrm{MV}$ and $\mathrm{SD}$ of spontaneous MN/1000 BNC were assessed in each group of subjects. An unpaired t-test also was employed to compare the $\mathrm{MN} / 1000 \mathrm{BNC}$ in Botteng Village inhabitants and control samples at, before, and after irradiation. The Kolmogorov-Smirnov test was applied to establish the distribution of data. All tests were conducted using the Statistical Package for the Social Sciences (SPSS) for Windows, version 22.0. A P value $\leq 0.05$ was considered the significance level.

\section{Samples Characteristics}

Statistical analysis revealed that gender and age status in the Botteng Village inhabitants and control samples was not significantly different $(p>0.05)$. The mean age of the Botteng Village inhabitants was $43.55 \pm 4.86$ with a range from 23 to 70 years. The mean age of the controls ranged from 17 to 70 years with a mean of $48 \pm 4.17$.

\section{Lymphocytic Radiosensitivity}

The spontaneous MN/1000 BNC in Botteng Village inhabitants was higher compared to the control group even though the difference was not significant $(p=0.25)$ (Fig. 1). However, a significant difference was found when comparing MN/1000 BNC after 1.5 Gy exposure and radiation-induced $\mathrm{MN}$ between Botteng Village inhabitants and control samples $(p \leq 0.0001 ; p \leq 0.0001)$ (Figure 1). In the present work, the upper and lower cutoff values to define individual radiosensitivity were 241.52 and 73.56 , respectively, derived from the mean value of the radiation-induced $\mathrm{MN}$ in the control group $157.5 \pm(2 \times 41.9)$. The mean value of the radiationinduced $\mathrm{MN}$ found in the control group of our study was higher compared to Encheva et al. (2012), that only reached $99.7 \pm 19.1$. Based on the arbitrary cut-off values, six out of 11 inhabitants in the HBRA group exhibited resistance to the challenge dose, whereas five other inhabitants had normal radiosensitivities (Tab. 1). Interestingly, in the control group, all samples were demonstrated to have normal sensitivities (Tab. 2). 
Table 1. The MN/1000 BNC before and after exposure to $1.5 \mathrm{~Gy}$ in Botteng Village inhabitant (HBRA) samples.

\begin{tabular}{ccccc}
\hline $\begin{array}{c}\text { Sample number (age, } \\
\text { gender) }\end{array}$ & $\begin{array}{c}\text { Spontaneous MN/1000 } \\
\text { BNC }\end{array}$ & $\begin{array}{c}\text { MN/1000 BNC after 1.5 } \\
\text { Gy irradiation }\end{array}$ & Radiation-induced MN & $\begin{array}{c}\text { Lymphocytic } \\
\text { radiosensitivity category }\end{array}$ \\
\hline $1(27, \mathrm{M})$ & 41 & 153 & 112 & Normal \\
$2(40, \mathrm{~F})$ & 59 & 128 & 69 & Resistant \\
$3(61, \mathrm{M})$ & 44 & 74 & 30 & Resistant \\
$4(52, \mathrm{~F})$ & 40 & 177 & 137 & Normal \\
$5(28, \mathrm{~F})$ & 36 & 131 & 95 & Normal \\
$6(30, \mathrm{M})$ & 43 & 138 & 95 & Normal \\
$7(63, \mathrm{M})$ & 38 & 70 & 32 & Resistant \\
$8(23, \mathrm{~F})$ & 45 & 68 & 23 & Resistant \\
$9(45, \mathrm{M})$ & 50 & 119 & 69 & Resistant \\
$10(40, \mathrm{M})$ & 20 & 107 & 87 & Normal \\
$11(70, \mathrm{~F})$ & 24 & 64 & 40 & Resistant \\
\hline
\end{tabular}

F: Female, M: Male

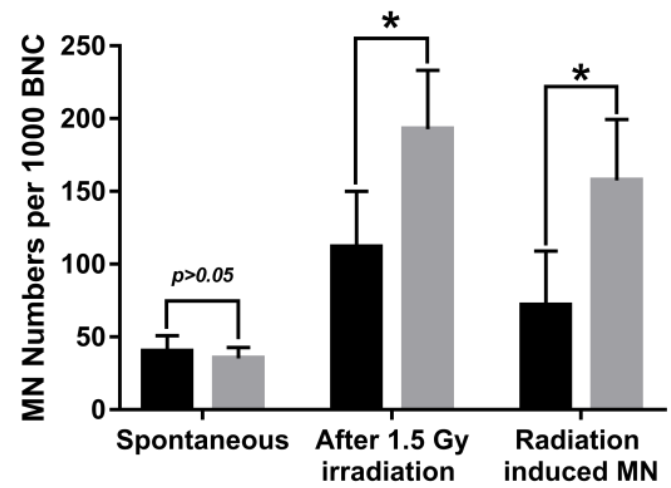

Botteng Village Inhabitants

Control

Figure 1. The mean MN/1000 BNC before and after exposure to 1.5 Gy of Botteng Village inhabitants (HBRA) and control samples (*: significantly different, $p<0.05)$.

Table 2. The MN/1000 BNC before and after exposure to $1.5 \mathrm{~Gy}$ in control samples.

\begin{tabular}{|c|c|c|c|c|}
\hline $\begin{array}{c}\text { Sample number (age, } \\
\text { gender) }\end{array}$ & $\begin{array}{c}\text { Spontaneous MN/1000 } \\
\text { BNC }\end{array}$ & $\begin{array}{l}\text { MN/1000 BNC after } 1.5 \\
\text { Gy irradiation }\end{array}$ & Radiation-induced MN & $\begin{array}{c}\text { Lymphocytic } \\
\text { radiosensitivity category }\end{array}$ \\
\hline $1(43, \mathrm{~F})$ & 37 & 112 & 75 & Normal \\
\hline $2(55, \mathrm{M})$ & 30 & 185 & 155 & Normal \\
\hline $3(43, F)$ & 46 & 220 & 174 & Normal \\
\hline $4(40, M)$ & 34 & 181 & 147 & Normal \\
\hline $5(40, \mathrm{~F})$ & 33 & 262 & 229 & Normal \\
\hline $6(60, F)$ & 39 & 164 & 125 & Normal \\
\hline $7(55, \mathrm{~F})$ & 49 & 208 & 159 & Normal \\
\hline $8(70, \mathrm{~F})$ & 22 & 237 & 215 & Normal \\
\hline $9(55, \mathrm{M})$ & 33 & 204 & 171 & Normal \\
\hline $10(17, \mathrm{M})$ & 35 & 165 & 130 & Normal \\
\hline $11(50, \mathrm{~F})$ & 30 & 183 & 153 & Normal \\
\hline Mean Value \pm SD & $35.2 \pm 7.5$ & $192.8 \pm 40.3$ & $157.5 \pm 41.9$ & \\
\hline
\end{tabular}

F: Female, M: Male 


\section{Discussion}

In this study, we identified that more than $50 \%$ of HBRA samples were demonstrated to have low radiosensitivities. This outcome of resistance may be based on highly efficient DNA repair processes (Rodgers \& Holmes, 2008). Masoomi et al. (2006) evaluated DNA repair in Ramsar inhabitants by comet assay. In their study, they observed that Ramsar inhabitants who had received a lower chronic dose (ranging from 0.53 to 7.62 $\mathrm{mSv} / \mathrm{y}$ ) exhibited less radiosensitivity and a greater DNA repair rate compared to control samples. Seeing that in this study, people living in Botteng Village received 3.83 $\mathrm{mSv} / \mathrm{y}$, it is possible that DNA repair in Botteng Village inhabitants was more efficient than in the control samples. Another investigation performed by Mohammadi et al. (2006) revealed that the $\mathrm{MN}$ frequencies in lymphocytes of Ramsar inhabitants were significantly lower compared to those living in NBRAs after exposure to a 4 Gy $\gamma$-Ray challenging dose. This result indicated that chronic low radiation exposure, or regarded as priming irradiation in Ramsar inhabitants, could induce less susceptibility of lymphocytes to the challenging dose. Mohammadi et al. (2006) concluded that based on their study results, it was possible that RAR might be brought about in people living in HBRAs. Similar to Mohammadi et al. (2006), herein, we also found a significant difference in MN/1000 BNC of Botteng Village inhabitants compared to control samples after 1.5 Gy exposure. Thus, our study supports Mohammadi et al. (2006)'s findings.

It was also observed in our study that individual variations across all samples existed, thereby representing different individual sensitivities to genotoxic agents and also a difference in DNA damage repair capacity (Encheva et al., 2012). Our study also uncovered how radiosensitivity was not age related as the age of Botteng Village inhabitants categorized as resistant were within the range of 24-59. Gender factor was also not correlated with individual radiosensitivity because Botteng Village inhabitants categorized as resistant were comprised of three males and females. This finding was in contrast with another study that found a correlation between radiosensitivity and gender (Alsbeih et al., 2016). They determined that females are slightly but significantly more radiosensitive compared to males. The sample size factor may suggest that in this study, a difference in radiosensitivity between females and males was not established. The sample size employed in this study may not be adequate enough to show the correlation between radiosensitivity and gender. As this study is considered a pilot study involving only 11 samples, the number of samples used also signifies a limitation of the current work. It is possible that utilizing a larger sample size will permit the finding of a correlation between radiosensitivity and gender.

It is well-known that the priming dose indeed induced radioadaptation in the six persons of this study, but it was not completely protective to all samples from Botteng Village, Mamuju. These reflect the importance of radiation dose values when evaluating both chromosomal damage and RAR. Herein, we used 1.5 Gy of gamma rays, a value also used in other studies (Encheva et al.,
2012; Ryabchenko et al., 2012). The employment of higher radiation doses should be conducted in further studies to confirm that RAR was developed in Mamuju inhabitants. It is possible that using $2 \mathrm{~Gy}$ or higher irradiation doses will yield different results. Making use of the $\mathrm{G}_{0} \mathrm{MN}$ assay, Mozdarani et al. (2005) found a significant difference in terms of lymphocytic radiosensitivity between a control group and groups of breast cancer or oesophageal cancer patients with 3 Gy in vitro irradiation. In a study by Herd et al. (2016), the increase of chromosomal radiosensitivity in HIV-positive South African cervical cancer patients using the $\mathrm{G}_{0} \mathrm{MN}$ assay after in vitro irradiation of lymphocytes with 2 and 4 Gy was also revealed. Further investigation using higher radiation dose values and a greater sample number should be conducted in order to validate the RAR phenomena in lymphocytes of Botteng Village inhabitants.

Lymphocytic radiosensitivity in this study was measured based on a $\mathrm{G}_{0}$ assay, where cells are irradiated in $\mathrm{G}_{0}$ that is then followed by stimulation of the cell cycle with phytohaemagglutinin (PHA). Radiosensitivity as determined by the $\mathrm{G}_{0}$ assay is considered to signify the amount of cell death induced by ionizing radiation. $G_{0}$ radiosensitivity is assumed to primarily depend on nonhomologous end-joining (NHEJ) as the dominant DNA double strand break (DSB) repair pathway during $\mathrm{G}_{0} / \mathrm{G}_{1}$ phase (Borgmann et al., 2010). For this reason, lymphocytic radiosensitivity is greatly influenced by genetic factors (Mumbrekar et al., 2016). Variations in lymphocytic radiosensitivity can be attributed to polymorphisms in DNA repair genes (Mumbrekar et al., 2016). Mumbrekar et al. (2016) study showed that two selected single nucleotide polymorphisms (SNPs), specifically rs2267437 in XRCC6 and rs1805388 in LIG4, were associated with increased initial DSB damage and enhanced radioresistance in the lymphocytes of healthy individuals. These two genes belong to the NHEJ repair pathway, which is the main DSB repair mechanism involved in the removal of radiation-induced DSBs in higher eukaryotes. Is it possible that the variation of individual radiosensitivity status in Botteng Village inhabitants found in this study was correlated with genetic factors, mainly the SNPs of genes involved in NHEJ repair pathway. Investigation of the SNPs of genes implicated in the NHEJ repair pathway should be studied further.

The data reported here describes an assessment of lymphocytic radiosensitivity using the $\mathrm{G}_{0} \mathrm{MN}$ assay in community members of Mamuju. The MN assay can be used to detect the DNA damage induced by ionizing radiation and its repair processes. The method is particularly useful for detecting unrepaired DSB, that is the primary lesions of concern, and relatively simple to conduct (Fenech, 2007). It is well-documented that ionizing radiation increases the incidence of $\mathrm{MN}$ in vivo and in vitro where during irradiation, both hydrogen peroxide and hydroxyl free radicals can directly or indirectly cause DNA damage (Fenech, 2002). The simple investigation of our study was intended to assess the observed response of peripheral blood lymphocytes in 
adapting to high natural radiation and it is necessary to accurately evaluate risks associated with long-term exposure to low dose and low dose-rate radiation by local inhabitants. However, the use of another assay, like the $\mathrm{G}_{2}$ MN assay, should also be investigated to determine the RAR phenomenon in Mamuju inhabitants. Different from the $\mathrm{G}_{0}$ assay, the $\mathrm{G}_{2} \mathrm{MN}$ assay was optimized to detect defects during $S$ or $G_{2}$ phase of the cell cycle. Using this assay, Claes et al. discerned increased radiosensitivity in a patient with a mild form of ataxiatelangiectasia (A-T)
(Claes et al., 2013). Overall, it can be concluded that the $\mathrm{G}_{0} \mathrm{MN}$ assay can be applied to evaluate lymphocytic radiosensitivity in Botteng Village inhabitants. Further investigation using a larger sample size and higher irradiation dose should be performed to confirm the RAR phenomenon in Botteng Village inhabitants. Additional investigation of polymorphisms in DNA repair genes also should be conducted in lymphocytes of Botteng Village inhabitants to understand the influence of genetic factors on lymphocytic radiosensitivity status.

\section{Acknowledgment}

The authors gratefully acknowledge the Center for Technology of Radiation Safety and Metrology (PTKMR). This study was supported by grants from the National Nuclear Energy Agency of Indonesia (Badan Tenaga Nuklir Nasional), contract number 080.01.06 3447.001 001.052.A, and conducted as a BATAN Annual Research Project in 2016.

\section{References}

Alsbeih, G., Al-meer, R. S., Al-harbi, N., Bin, S., Al-buhairi, M., Venturina, N. Q., \& Moftah, B. (2016). Gender bias in individual radiosensitivity and the association with genetic polymorphic variations. Radiotherapy and Oncology, 119(2), 236-243.

Baert, A., Depuydt, J., Van Maerken, T., Poppe, B., Malfait, F., Storm, K., \& Vral, A. (2016). Increased chromosomal radiosensitivity in asymptomatic carriers of a heterozygous BRCA1 mutation. Breast Cancer Research, 18(1), 52.

Basri, I. K. H., Yusuf, D., Rahardjo, T., Nurhayati, S., Tetriana, D. Ramadhani, D., \& Syaifudin, M. (2017). Study of $\gamma-\mathrm{H} 2 \mathrm{AX}$ as DNA double strand break biomarker in resident living in high natural radiation area of Mamuju, West Sulawesi. Journal of Environmental Radioactivity, 171, 212-216.

Borgmann, K., Raabe, A., Reuther, S., Szymczak, S., Schlomm, T. Isbarn, H., ... Dikomey, E. (2010). The potential role of G2- but not of G0-radiosensitivity for predisposition of prostate cancer. Radiotherapy and Oncology, 96(1), 19-24.

Choi, V. W. Y., Wong, M. Y. P., Cheng, S. H., \& Yu, K. N. (2011) Dosimetric study of radioadaptive response of zebra fish embryos using PADC-film substrates. Radiation Measurements, 46, 1795-1798.

Claes, K., Depuydt, J., Taylor, A. M. R., Last, J. I., Baert, A., Schietecatte, P., \& Vral, A. (2013). Variant Ataxia Telangiectasia: Clinical and Molecular Findings and Evaluation of Radiosensitive Phenotypes in a Patient and Relatives. NeuroMolecular Medicine, 15(3), 447-457.

Encheva, E., Deleva, S., Hristova, R., Hadjidekova, V., \& Hadjieva, T. (2012). Investigating micronucleus assay applicability for prediction of normal tissue intrinsic radiosensitivity in gynecological cancer patients. Reports of Practical Oncology and Radiotherapy, 17, 24-31.

Fenech, M. (2002). Chromosomal biomarkers of genomic instability relevant to cancer. Drug Discovery Today, 7(22), 1128-1137. Retrieved from https://www.sciencedirect.com/science/article/pii /S1359644602025023

Fenech, M. (2007). Cytokinesis-block micronucleus cytome assay. Nature Protocol, 2(5), 1084-1104.

Hendry, J. H., Simon, S. L., Wojcik, A., Sohrabi, M., Cardis, E., Laurier, D., \& Hayata, I. (2009). Human exposure to high natural background radiation: what can it teach us about radiation risks? Journal of Radiological Protection, 29, A29-A42.

International atomic energy agency. (2011). Cytogenetic Dosimetry: Applications in Preparedness for and Response to Radiation Emergencies. Vienna: International atomic energy agency. Retrieved from http://www-pub.iaea.org/books/IAEABooks/ 8735/Cyto genetic-Dosimetry-Applications-in-Preparedness-forand-Response-to-Radiation-Emergencies
Masoomi, J. R., Mohammadi, S., Amini, M., \& Ghiassi-nejad, M. (2006). High background radiation areas of Ramsar in Iran : evaluation of DNA damage by alkaline single cell gel electrophoresis (SCGE). Journal of Environmental Radioactivity, $86,176-186$

Mohammadi, S., Taghavi-dehaghani, M., Gharaati, M. R., Masoomi, R., \& Ghiassi-Nejad, M. (2006). Adaptive Response of Blood Lymphocytes of Inhabitants Residing in High Background Radiation Areas of Ramsar- Micronuclei , Apoptosis and Comet Assays. Journal of Radiation Research , 47(3-4), 279-285.

Mortazavi, S. M. J., Ghiassi-Nejad, M., Ikushima, T., Assaie, R., Heidary, A., Varzegar, R., \& Esmaili, A. (2003). Are the Inhabitants of High Background Radiation Areas of Ramsar More Radioresistant? Iranian Journal of Radiology, $1(1$ \& 2), 37-43. Retrieved from http://iranjradiol.com/en/articles/ 79279.html

Mortazavi, S. M. J., \& Mozdarani, H. (2012). Is it time to shed some light on the black box of health policies regarding the inhabitants of the high background radiation areas of ramsar? Iranian Journal of Radiation Research, 10(3-4), 111-116. Retrieved from http://ijrr.com/browse.php?a_id=976\&sid=1\&slc_lang=en

Mozdarani, H., Mansouri, Z., \& Haeri, S. A. (2005). Cytogenetic Radiosensitivity of G0-Lymphocytes of Breast and Esophageal Cancer Patients as Determined by Micronucleus Assay. Journal of Radiation Research, 46, 111-116. Retrieved from https://www.jstage.jst.go.jp/article/jrr/46/1/46_1_111/_article

Mumbrekar, K. D., Goutham, H. V., Vadhiraja, B. M., \& Sadashiva, S R. B. (2016). Polymorphisms in double strand break repair related genes influence radiosensitivity phenotype in lymphocytes from healthy individuals. DNA Repair, 40, 27-34.

Nurhayati, S., Purnami, S., \& Syaifudin, M. (2016). Cytogenetic Evaluation in Peripheral Blood Lymphocytes of Individuals living in high natural background radiation of Botteng Village, Mamuju. In Y. Suzuki, R. A. Jeffry, H. Suseno, Budiawan, F. Haryanto, J. R. Dumais, \& A. Masaitullah (Eds.), International Conferences on the Sources, Effects and Risks of Ionizing Radiation 2 (SERIR 2) (pp. 80-84). Sanur, Bali: Center for Technology of Radiation Safety and Metrology.

Poggioli, T., Sterpone, S., Palma, S., Cozzi, R., \& Testa, A. (2010). G0 and G2 Chromosomal Assays in the Evaluation of Radiosensitivity in a Cohort of Italian Breast Cancer Patients. Journal of Radiation Research, 51, 615-619.

Rahardjo, T., Mailana, W., Kisnanto, T., Darlina, D., Nurhayati, S., Tetriana, D., \& Syaifudin, M. (2017). Assessment of DNA damage in lymphocytes of Mamuju (a high background radiation area) inhabitants using alkaline single cell gel electrophoresis. International Journal of Low Radiation, 10(4).

Rodgers, B., \& Holmes, K. (2008). Radio-Adaptive Response To Enviromental Exposures At Chernobyl. Dose-Response, 6, 209221.

Ryabchenko, N. M., Glavin, O., Shtefura, V. V, \& Anikusko, M. F. (2012). Chromosomal Radiosensitivity in Ukranian Breast Cancer Patients and Healthy Individuals. Experimental Oncology, 34(2), 121-124.

Sadiq, A., \& Termizi, A. (2015). The world's high background natural radiation areas ( HBNRAs ) revisited: A broad overview of the dosimetric , epidemiological and radiobiological issues. Radiation Measurements, 73, 51-59.

Syaeful, H., Sukadana, I. G., \& Sumaryanto, A. (2014). Radiometric Mapping for Naturally Occurring Radioactive Materials 
(NORM) Assessment in Mamuju, West Sulawesi. Atom Indonesia, 40(1), 33-39.

UNSCEAR. (2000). REPORT Vol. I sources and effects of ionizing radiation, annex a: dose assessment methodologies. New York: United Nations Scientific Committee on the effects of atomic radiation. Retrieved from http://www.unscear.org/docs/ publications/2000/UNSCEAR_2000_Report_Vol.I.pdf

UNSCEAR. (2008). Sources and Effects of Ionizing Radiation: Sources
Annex B. Exposures of the Public and Workers from Various Sources of Radiation. United Nationas Publications (Vol. 1). Retrieved from http://www.unscear.org/docs/publications/2008/ UNSCEAR_2008_Report_Vol.I.pdf

Wodarz, D., Sorace, R., \& Komarova, N. L. (2014). Dynamics of Cellular Responses to Radiation. Plos Computational Biology, $10(4), 1-11$. 